\title{
Motivates President University StudentToward Chinese Food In Beijing Restaruant
}

\author{
Chen XiaoQi \& ZouZhiYu; Suresh Kumar \\ FacultyofBusiness President University Jalan Ki HajarDewantoroLemahabang, West Java 17550 Bekasi- \\ Indonesia
}

\begin{abstract}
Motivates President University students eat in Beijing restaurant inducement. There have several restaurants beside Beijing restaurant. However, Beijing restaurant has majority students order in there. This study investigation motivate of President University students come to Beijing restaurant constantly. This research purpose discuss about Beijing restaurant analysis account of students has dinner in here and improves the service and quality of food. A survey has done by research through e-mail to investigation for President University students. This study literature relative source from tasty of food, physical environment, service on restaurant image and customer perceived to research with this dissertation. Methodology base by two types, primary is consult student from President University face to face random drawing, secondary is basic on email pattern give to President University students. There are four factors being asked by informant which is freshness, tasty, healthy and food preparation of Beijing restaurant. The result of study indicates students come to Beijing restaurant high relative with tasty and food preparation.
\end{abstract}

\section{Introduction:}

Researches for students who are going to Beijing Restaurant dine in Citywalkfrom President University Students want to have a meal in Beijing Restaurant potential tendency; this purpose will study through this research main direction. Most of student would like have dinner in Beijing Restaurant instead of other restaurant from China. Beijing Restaurant is very potential restaurant in Citywalk Street of President University. The turnover of Beijing Restaurant is exceeding PanPan Restaurant which has same target with Beijing Restaurant.

President University is a university located in Jababeka Education Park in Kota Jababeka, Indonesia.It is surrounded by the Jababeka Industrial Estate with more than 1,500 national as well as multinational companies from 30 nations, such as Mulia, Unilever, Samsung, Mattel, ICI Paint, Kraft and othersconceived in 1997 and launched in 2001 as the School of Engineering in Cikarang, Bekasi, the school received University status on 16 April 2004.(President University about us, 2013)

There are so many different kinds of restaurants beside the President University's Student housing. Beijing Restaurant is one of special restaurant and located the City Work in front of President University's Student Housing. It is Chinese restaurant.

For all the PU's students, most of them are live in the Student Housing, some of them live outside. But there is no problem for the restaurant to get their customers. We know nowadays there are so many Chinese Restaurants in the world, some of which have become increasingly popular in other parts of the world. Chinese food is very emphasizes color, aroma, tastes great. This is a dish of standard and a dish I standard.

Those Chinese food color refers to the color of the dishes, is ecru match with the color of the ingredients of organic raw materials, sometimes with some green vegetables, tomatoes, Onions and other foil, in order to achieve a better visual effect. Chinese food perfume refers to the aroma of dishes, including gas incense and bone. Chinese food taste refers to the flavor of the dishes taste, is the soul of the dishes. It is the cooked dishes and spices as well as the product of the combination of different cooking methods. Chinese food meaning lets a person associate or a meaningful suggestion. Chinese food shape is segmented from the color of the slowly, is mainly pays attention to into the shape of a dish and decoration; For most people's understanding, the Chinese restaurant to open in foreign countries, are attracting some foreign businessmen, overseas Chinese, as well as locals. However, like such restaurants open in the school, the main consumers are students; it would have been very attractive research topic.

We know that a restaurant is not only rely on food to attract customers, and the environment of the restaurant, decorated like a restaurant, as well as equipment placed is neat is very important. Also, the restaurant waiter service attitude also plays a very important role.

There are around 12 restaurants in front of Student Housing, includes two Chinese restaurants, Beijing Restaurant is one of Chinese restaurant. Beijing restaurants the size of the restaurant size almost, restaurant equipment is also very complete, very comfortable environment, giving a warm feeling, and people feel very 
good. Every day there are so many students choose Beijing Restaurant for eating, this phenomenon made me curious, why so many of my students have chosen this restaurant. Chinese students should not feel anything strange, because this is the Chinese restaurant.

students.

So, researcher would like to investigate the restaurant why so welcomed by President University's

A major study of this research talking about what element makes Beijing Restaurant so attractive. The ability to attract and maintain customers is essential to the success of a restaurant. You need a constant flow of customers coming into your restaurant on a daily basis. Just posting an 'Open' sign in the front window is not enough to attract customers. Literature review will include some option about tasting as a projective technique, factors of influence customer perceived value and customer loyalty.

\subsection{Problem Identification}

We know that a restaurant is not only rely on food to attract customers, and the environment of the restaurant, decorated like a restaurant, as well as equipment placed is neat is very important. Also, the restaurant waiter service attitude also plays a very important role.

There are around 12 restaurants in front of Student Housing, includes two Chinese restaurants, Beijing Restaurant is one of Chinese restaurant. Beijing restaurants the size of the restaurant size almost, restaurant equipment is also very complete, very comfortable environment, giving a warm feeling, and people feel very good. Every day there are so many students choose Beijing Restaurant for eating, this phenomenon made me curious, why so many of my students have chosen this restaurant. Chinese students should not feel anything strange, because this is the Chinese restaurant.

So, researcher would like to investigate the restaurant why so welcomed by President University's students.

\subsection{Statement of the Problem}

This study aimed to determine the factors of the taste value that motivate the students.

Specifically, it shed answers to the following:

1. What is the demographic profile of the respondents in terms of:

$1.1 \quad$ Age

1.2 Sex

1.3 Nationality

1.4 Course

2. What are the factors that motivate taste value in terms of :

2.1 Freshness

2.2 Tasty

2.3 Healthy

2.4 Food Preparation

Is there any significance difference between taste value and motivation of the students of the food in the Beijing Restaurant?

Hypothesis

There is no significant different between taste value and motivation of the students of the food in the Beijing Restaurant.

\subsection{Significance of the Study}

This research focused on taste value that motivates president university student toward Chinese food in Beijing restaurant. Another would be to contribute to the taste value of the restaurant.

This study was significant to the following:

1. Students: The food is fresh, healthy, nutrition is very important, and students is because of this several reasons, often come to this restaurant.

2. The PU:Schools can bring clean restaurants for students, so that students can be safe dietary conditions, better growth in school and learning well.

3. Researcher: The product of this study will serves as a contribution to enhance therestaurant grassroots management, better asked the inadequacies of the restaurant improvement.

4. Respondent: Most of the respondents said Beijing restaurant food is fresh, healthy, and nutritious, helps the body's needs. Every day can eat safety of food, for everyone is happy.

5. Beijing Restaurant: As a restaurant, because of their own food safety, and to attract students visit the same things that make people happy. Healthy food standards to protect the health of students.

\subsection{Scope and Limitation of the Study}

This study was directed towards finding out the taste value that motivates president university student toward Chinese food in Beijing restaurant. The researcher focused on the giving attention to the students of 
President in all level with randomly selected into 30 respondents.

\section{Literature Review:}

2.0 Review of Related Literature and Study

This chapter presents the literature and studies of motivation for taste value.

\subsection{Foreign literature}

\section{Tasting as a projective technique}

Tasting as a projective technique is testing about tasting as a projective technique in explicating consumers' thoughts and feelings towards food and beverage products.

Based on Pettigrew is to investigate the benefits of tasting as a projective technique in explicating consumers' thoughts and feelings towards food and beverage products.

According to Tasting as a projective technique that shows ten focus groups were conducted with 35 consumers, 14 wine producers, and 13 mediators. The mediator category included those involved in marketing, wholesaling, retailing, and judging wine. Participants in each focus group were given the same four wines to taste. Initially they were invited to discuss their views on wine quality. The participants were then presented with the wines and asked to discuss their responses to them, particularly their perceptions of the quality of the wines.

Based on Pettigrew is findings related to: the changes in apparent certainty levels amongst professionals and high-involvement informants; exposure of real and contradictory preferences; role of cognitive, affective, and sensory responses to wine; and interpretation of the language of tasting. (Pettigrew, 1998)

The influence of the quality of the physical environment, food, and service on restaurant image, customer perceived value, customer satisfaction, and behavioral intentions.

Ryu purpose is to propose an integrated model that examines the impact of three elements of foodservice quality dimensions (physical environment, food, and service) on restaurant image, customer perceived value, customer satisfaction, and behavioral intentions.

As our research investigation is discuss about food, service and speed of offer food. The research ofRyu was helping us gain the model of study Beijing Restaurant.

Based onRyu research, the quality of the physical environment and food were significant predictors of customer perceived value. The restaurant image was also found to be a significant antecedent of customer perceived value. In addition, the results reinforced that customer perceived value is indeed a significant determinant of customer satisfaction, and customer satisfaction is a significant predictor of behavioral intentions. According to the proposed model and study findings will greatly help researchers and practitioners understand the complex relationships among foodservice quality (physical environment, food, and service), restaurant image, and customer perceived value, customer satisfaction, and behavioral intentions in the restaurant industry.(Kisang Ryu, International Journal of Contemporary Hospitality Management, 2012)

\section{Fruit and snack consumption related to sweet, sour and salty taste preferences}

According to the Siet J. Sijtsema (2012) that Mr.J said we should to better understand fruit consumption and its determinants this paper aims to explore the relationship (Sijtsema, 2012)between the consumption of different types of fruit and other snacks and consumer taste preferences for sweet, salty and sour is explored.

Based on Fruit and snack consumption related to sweet, sour and salty taste preferences - Respondents $(n=2,083)$ from Poland, Greece, Spain and The Netherlands filled out an online questionnaire in which the consumption of fresh fruit, sweet snacks, salty snacks, orange juice and dried fruit was measured as well as consumer selfreported taste preferences and personal orientations towards health, convenience, price and routine behaviors.

According to theSijtsema (2012) that a total of 29 percent of the total sample preferred salty tastes, whereas 21 percent preferred sweet tastes; 1 percent preferred sour tastes, and 39 percent indicated no preference. In contrast with the expectation that people who preferred sweet tastes consume more fruits and fruit products, the results imply that consumers with a sour taste preference consume more fruits and fruit products. In addition, consumers with a sour taste preference seem to be less convenience-oriented and have more routine behaviors with regard to fruit. In contrast, consumers with a sweet taste preference eat more chocolate bars and are more convenience-oriented.

Based on Fruit and snack consumption related to sweet, sour and salty taste preferences - The selfreported measurement of taste preferences requires further justification to be used as a measurement instrument, e.g. formulation of the items, different cultures and linkage with preferences based on sensory testing.

Practical implications - These findings show that the sweet tooth hypothesis is much more complicated if we consider not only consumption, but also self-reported taste preferences. (Kisang Ryu, International Journal of Contemporary Hospitality Management, 2012) 


\section{Reasons behind consumers' functional food choices}

According to Reasons behind consumers' functional food choices study was to examine what reasons consumers give for either choosing or not choosing functional foods. Laddering interviews were used to find out how consumers described their reasons for choosing functional food alternatives in different product categories and how these descriptions are linked with values. Yoghurt, spread, juice, carbonated soft drinks, sweets and ice cream were used as example product categories. In total, five central means-end chains, describing the product attributes, consequences and values behind respondents' food choices, were found, which referred to healthiness, taste and pleasure, security and familiarity, convenience and price. They were found to be independent from each other and had different connotations depending on the product category. The results indicate that respondents did not see functional foods as one homogenous group over different product categories. Instead, consumers seemed to perceive functional products as a member of the general product category such as yoghurt or spread and only secondarily as a functional food.(Nina Urala, 2003)

\section{Perceived health benefits and food purchasing decisions}

According to perceived health benefits and food purchasing decisions is to investigate the relative importance to consumers of different health benefits of food. Based on Darian (2011) - This study uses conjoint analysis to investigate the relative importance of five health benefits to consumers in their intention to buy a food.

According to perceived health benefits and food purchasing decisions - The results suggest that the single most important health benefit influencing purchase intentions is high nutritional value. If two health benefits are to be promoted, for the total sample the most effective combination would be high nutritional value and the potential to reduce cancer, followed by high nutritional value and proven to reduce the risk of heart disease. However, for those respondents with less than a college education, the most effective combination would be high nutritional value and the potential to reduce arthritis.

According to perceived health benefits and food purchasing decisions - More effective marketing of health benefits of foods should increase consumption of healthy foods, which will enhance consumer welfare. Based on Darian (2011) and Conjoint analysis has not previously been used in studies of this topic. The advantage of conjoint analysis over other analytical techniques is that it incorporates realistic trade-offs when measuring consumer preferences.(Darian, 2011)

\section{Customer loyalty and customer loyalty programs}

According to uncles Customer loyalty presents a paradox. Many see it as primarily an attitude-based phenomenon that can be influenced significantly by customer relationship management initiatives such as the increasingly popular loyalty and affinity programs. However, empirical research shows that loyalty in competitive repeat-purchase markets is shaped more by the passive acceptance of brands than by strongly-held attitudes about them. From this perspective, the demand-enhancing potential of loyalty programs is more limited than might be hoped. Reviews three different perspectives on loyalty, and relates these to a framework for understanding customer loyalty that encompasses customer brand commitment, customer brand acceptance and customer brand buying. Use this framework to analyze the demand-side potential of loyalty programs. Discusses where these programs might work and where they are unlikely to succeed on any large scale. (Uncles, 2003)

\subsection{Theoretical Framework}

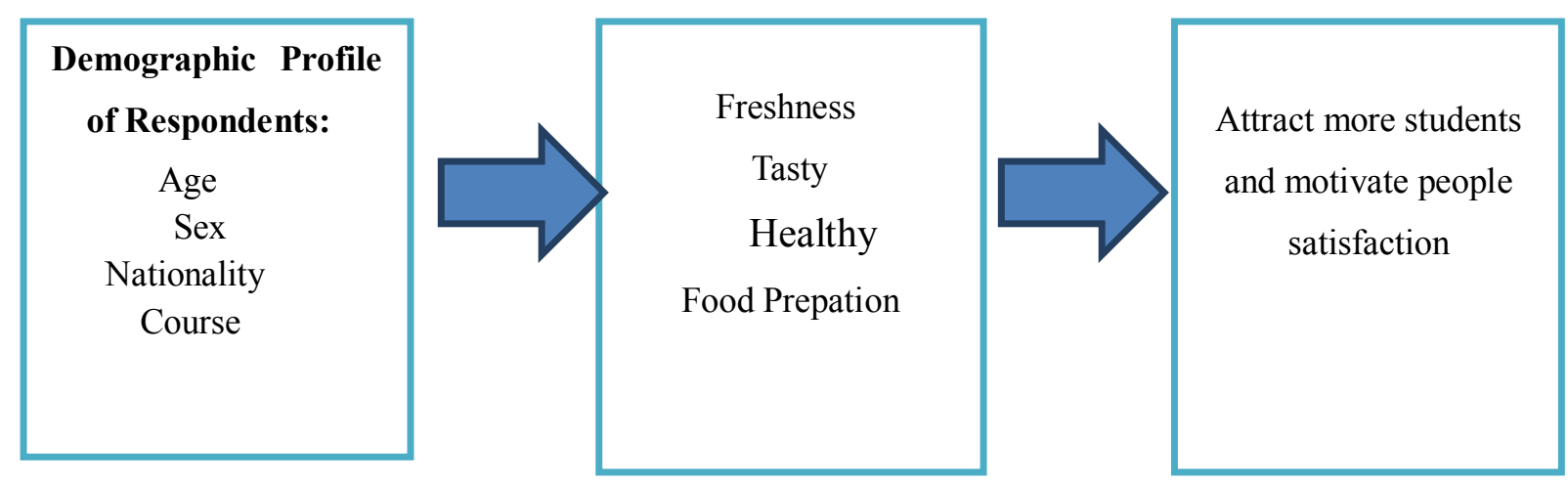

Fig. 1 Conceptual Paradigm Showing the Relationship of the Independent Variable and Dependent Variable 


\subsection{Managerial Application of Needs Theory}

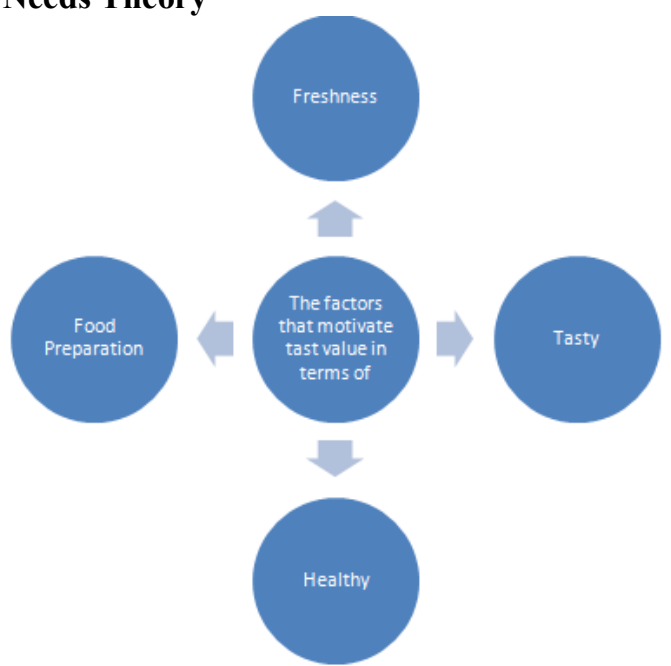

Fig. 2 Conceptual Paradigm showing the factors that motivate taste value in the Management Concepts

\subsection{Definition of Terms}

Food: Food is any substance consumed to provide nutritional support for the body. It is usually of plant or animal origin, and contains essential nutrients, such as carbohydrates, fats, proteins, vitamins, or minerals. The substance is ingested by an organism and assimilated by the organism's cells in an effort to produce energy, maintain life, or stimulate growth.

Health: Health is the level of functional or metabolic efficiency of a living being. In humans, it is the general condition of a person's mind and body, usually meaning to be free from illness, injury or pain.

Motivation: Motivation is a psychological feature that arouses an organism to act towards a desired goal and elicits, controls, and sustains certain goal directed behaviors. It can be considered a driving force; a psychological drive that compels or reinforces an action toward a desired goal.

Restaurant: A restaurant is an establishment which prepares and serves food and drink to customers in return for money, either paid before the meal, after the meal, or with a running tab. Meals are generally served and eaten on premises, but many restaurants also offer take-out and food delivery services. Restaurants vary greatly in appearance and offerings, including a wide variety of the main chef's cuisines and service models.

Student: A student is a learner, or someone who attends an educational institution. In some nations, the English term is reserved for those who attend university, while a schoolchild under the age of eighteen is called a pupil in English, although in the Unite Stated a person enrolled in grades K-12 is often called a student. In its widest, student is used for anyone who is learning.

Taste: In sociology, taste is an individual's personal and cultural patterns of choice and preference. Taste is about drawing distinction between things such as styles, manners, consumer goods and works of art. Social inquiry of taste is about the human ability to judge what is beautiful, good and proper.

\subsection{Research Design:}

\section{Methodology:}

This research used descriptive co relational research also known as statistical research. This describes data and characteristics about the population or phenomenon. This method is employed because it easily assessed student's satisfaction for Beijing Restaurant in City Work. This model-based quantitative research of causal relationship between control variable and performance variable developed, analyzed or tested. (Bertrand and Fransoo, 2002) 


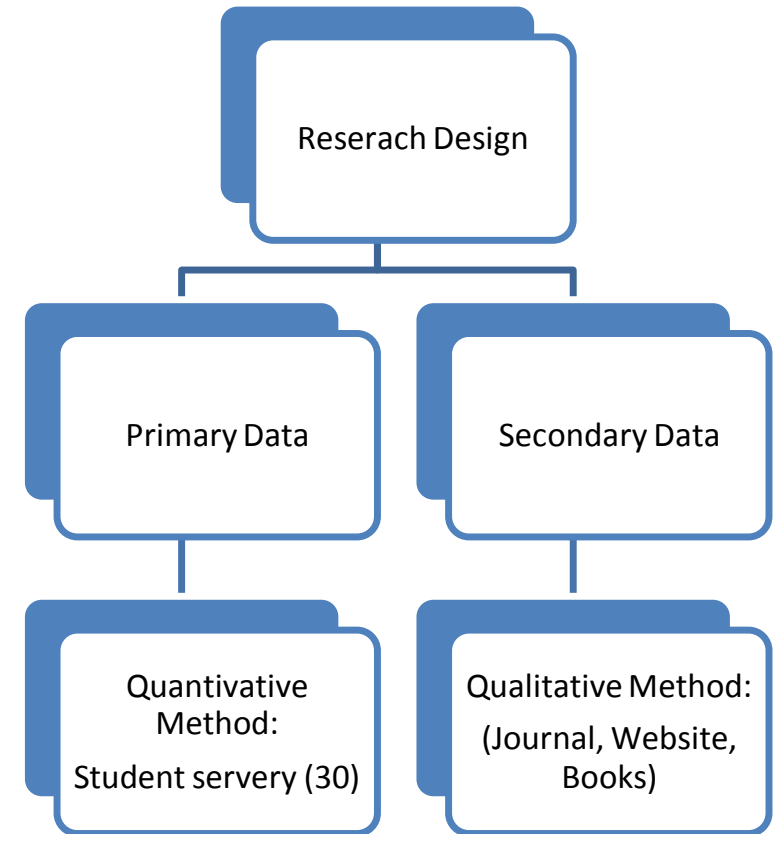

\subsection{Sampling:}

This study target population is students who study in President University in 2013. Simple random sampling was utilized in this study since it is a subset of individuals (a sample) chosen from a larger set (a population). Each individual is chosen randomly and entirely by chance, such that each individual has the same probability of being chosen at any stage during the sampling process, and each subset of $\mathrm{k}$ individuals has the same probability of being chosen for the sample as any other subset of $k$ individuals (Yates, Daniel S.; David S. Moore, Daren S. Starnes (2008). The Practice of Statistics, 3rd Ed..Freeman. ISBN 978-0-7167-7309-2.). This process and technique is known as simple random sampling, and should not be confused with Random sampling.

Disadvantages are that it is free of classification error, and it requires minimum advance knowledge of the population other than the frame. Its simplicity also makes it relatively easy to interpret data collected via SRS. For these reasons, simple random sampling best suits situations where not much information is available about the population and data collection can be efficiently conducted on randomly distributed items, or where the cost of sampling is small enough to make efficiency less important than simplicity. If these conditions are not true, stratified sampling or cluster sampling may be a better choice.

\subsection{Measures:}

The measures used were the set of questionnaire which was to gather data from the respondents. Questionnaire was composed of three parts that would be disseminated to the respondents. The first part will draw information about the demographic profile of the respondents. Second part will be the factors that motivate taste value of Beijing Restaurant in terms of. Part three will reveal answers to effectiveness of the student's satisfaction for Beijing Restaurant in the City Work.

\subsection{Data Collection Procedure:}

After the approval of the title, the researchers formulated a set of questionnaire based on the nature of the study. The letter certified to allow the researchers to disseminate questionnaire to the students needed for data collection. . The responses from the respondents based from the research instrument were tallied, analyzed and interpreted essential for the findings and conclusion of the study. Data collection includes both primary and secondary data. Secondary data is collected through the website, industry report to support the literature, and journals.

Primary data is collected through the questionnaire given to the 30 students in the President University. The majority of students are from Chinese around 20 and 10 foreigners who often order meal in Beijing restaurant. There have 23 male and 7 females. All of them age are around 20 to 25 . They are university students and merely without salary since study in college.

This secondary data collect from website of Google Drive, 208 portions has been gathering by research. There has 200 shares used in our investigation; the most of them are college students from President University, and minority of employee graduate from President University. Those respondents were collect around two weeks. 


\subsection{Data analysis:}

KMO and Bartlett's Test

\begin{tabular}{|cc|c|}
\hline \multicolumn{2}{|c|}{ Kaiser-Meyer-Olkin Measure of Sampling Adequacy. } & .527 \\
& Approx. Chi-Square & 608.120 \\
Bartlett's Test of Sphericity & $\mathrm{df}$ & 28 \\
& Sig. & .000 \\
\hline
\end{tabular}

KMO \& Bartlett's Test of Sphericity is a measure of sampling adequacy that is recommended to check the case to variable ratio for the analysis being conducted. In most academic and business studies, KMO \& Bartlett's test play an important role for accepting the sample adequacy. In this case, the KMO ranges about 0.527 ; the Bartlett's Test of Sphericity relates to the significance of the study and thereby shows the validity and suitability of the responses collected to the problem being addressed through the study.(Uddin, 2013)

\begin{tabular}{|l|r|r|}
\hline \multicolumn{3}{|c|}{ Communalities } \\
\hline Q2 & Initial & Extraction \\
Q3 & 1.000 & .872 \\
Q4 & 1.000 & .856 \\
Q6 & 1.000 & .847 \\
Q7 & 1.000 & .875 \\
Q8 & 1.000 & .855 \\
Q9 & 1.000 & .872 \\
Q12 & 1.000 & .844 \\
Extraction Method: Principal \\
\hline
\end{tabular}

Once the extraction of factors has been completed, we examine the table of 'Communalities' which tells us how much of the variance in each of the original variables is explained by the extracted factors. In this case, in the table shown below, $87.2 \%$ of the variance in the original Q2 'Delivery Speed' variable is explained by the two extracted components. Higher communalities are desirable. If the communality for a variable is less than $50 \%$, it is a candidate for exclusion from the analysis because the factor solution contains less than half of the variance in the original variable, and the explanatory power of that variable might be better represented by the individual variable.(utexas)

\section{Component Analysis.}

\begin{tabular}{|l|r|r|r|r|r|r|}
\hline \multirow{2}{*}{ Componen } & \multicolumn{3}{|c|}{ Initial Eigenvalues } & \multicolumn{3}{|c|}{ Rotation Sums of Squared Loadings } \\
\cline { 2 - 7 } & \multicolumn{1}{|c|}{ Total } & \% of Variance & Cumulative \% & \multicolumn{1}{c|}{ Total } & \% of Variance & Cumulative $\%$ \\
\hline 1 & 2.213 & 27.666 & 27.666 & 1.748 & 21.847 & 21.847 \\
2 & 2.075 & 25.942 & 53.607 & 1.725 & 21.567 & 43.413 \\
3 & 1.319 & 16.482 & 70.090 & 1.718 & 21.480 & 64.894 \\
4 & 1.274 & 15.921 & 86.010 & 1.689 & 21.117 & 86.010 \\
5 & .350 & 4.370 & 90.380 & & & \\
6 & .289 & 3.615 & 93.996 & & & \\
7 & .263 & 3.292 & 97.287 & & & \\
8 & .217 & 2.713 & 100.000 & & & \\
\hline
\end{tabular}

Extraction Method: Principal Component Analysis.

The "Total Variance Explained" table below shows the eigenvalues, which are the proportion of total variance in all the variables which is accounted for by that factor. A factor's eigenvalue may be computed as the sum of its squared factor loadings for all the variables. A factor's eigenvalue divided by the number of variables (which equals the sum of variances because the variance of a standardized variable equals 1) is the percent of variance in all the variables which it explains. The ratio of eigenvalues is the ratio of explanatory importance of the factors with respect to the variables. If a factor has a low eigenvalue $(<1.0)$, then it is contributing little to the explanation of variances in the variables and may be ignored as redundant with more important factors. The table shows 8 factors, one for each variable. However, only the first 4 are extracted for analysis because, under the Extraction options, SPSS was told to extract only factors with eigenvalues of 1.0 or higher. The "Rotation Sums of Squared Loadings" give the eigenvalues after rotation improves the interpretability of the factors (we used Varimax rotation, which minimizes the number of variables which have high loadings on each given factor). Note that the total percent of variance explained is the same (see the cumulative value for factor 4 -- 
$86.010 \%$ ) but rotation changes the eigenvalues for each of the extracted factors. That is, after rotation each extracted factor counts for a different percentage of variance explained, even though the total variance explained is the same.(coedpages, 2013)

\subsection{Conclusion:}

\section{Conclusion}

This study purpose discuss about motivates president university student toward Chinese food in Beijing Restaurant. Primary chapter introduction interpreted background of this study and list a hypothesis which is there have not relative tasty value and motivate with student who comes to Beijing restaurant dinner. Second chapter exposition literature from website research employ relative data to analysis this proposition. Third chapter employ methodology to collection data from students from President University. The result of this collection use SPSS instrument analysis indicates majority students more trend to Beijing restaurant due to their high level tasty and food preparation. It manifest students come to Beijing because of their high relative with flavor and food preparation. Freshness and healthy situate mid-level position. It manifest freshness and healthy have original relative with students who come to Beijing restaurant.

\section{Reference:}

[1]. President University about us. (2013). Retrieved 10 22, 2013, from President University: http://www.president.ac.id/about-us/

[2]. Charters, S. (2010). Asia Pacific Journal of Marketing and Logistics. Retrieved 10 22, 2013, from Emberald: http://www.emeraldinsight.com/journals.htm?articleid=1846901

[3]. coedpages. (2013). Illustration of Exploration Factor Analysis. Retrieved 11 22, 2013, from coedpages.

[4]. Darian, J. C. (2011). Journal of Consumer Marketing. Retrieved 10 22, 2013, from Emberald: http://www.emeraldinsight.com/journals.htm?articleid=1954175

[5]. Kisang Ryu, H.-R. L. (2012). International Journal of Contemporary Hospitality Management. Retrieved 10 22, 2013, from Emberald: http://www.emeraldinsight.com/journals.htm?articleid=17026181

[6]. Nina Urala, L. L. (2003). Nutrition \& Food Science. Retrieved 10 22, 2013, from Emberald: http://www.emeraldinsight.com/journals.htm?articleid=866201

[7]. Pettigrew, S. (1998). Qulitative market research. Retrieved 10 22, 2013, from Emerald: http://www.emeraldinsight.com/journals.htm?issn=1352-2752\&volume=11\&issue=3\&articleid=1729316\&show=abstract

[8]. Sijtsema, S. J. (2012). British Food Journal. Retrieved 10 22, 2013, from Emberld: http://www.emeraldinsight.com/journals.htm?articleid=17041607

[9]. Uddin, S. u. (2013, June 29). Factor analysis. Retrieved 11 21, 2013, from Business Analytics: http://badmforum.blogspot.com/2012/08/factor-analysis-kmo-bartletts-test.html

[10]. Uncles, M. D. (2003). Journal of Consumer Marketing. Retrieved 10 22, 2013, from Emerald : http://www.emeraldinsight.com/journals.htm?issn=0736-3761\&volume=20\&issue=4\&articleid=856461\&show=abstract

[11]. utexas. (n.d.). Factor Analysis (Communalities). Retrieved 11 21, 2013, from utexas: http://www.utexas.edu/courses/schwab/sw388r7/Tutorials/Principal_Components_Analysis_doc_html/029_Analysis_of_the_Comm unalities.html

[12]. zhun, 1. a. (2013, 10 22). zhong guo cai. Retrieved 10 25, 2013, from Baidu Baike: http://baike.baidu.com/subview/80165/11297045.htm? fromId=80165\&from=rdtself

\begin{tabular}{|c|c|c|c|c|c|}
\hline & SD & $\mathrm{D}$ & $\mathrm{F}$ & A & SA \\
\hline \multicolumn{6}{|l|}{ Freshness } \\
\hline \multicolumn{6}{|l|}{ Fresh ingredients. } \\
\hline \multicolumn{6}{|l|}{ The beverages are very clean. } \\
\hline \multicolumn{6}{|l|}{ The fruits are very fresh. } \\
\hline \multicolumn{6}{|l|}{ Tasty } \\
\hline \multicolumn{6}{|l|}{ The quality of food } \\
\hline \multicolumn{6}{|l|}{ Tasty and flavorful } \\
\hline \multicolumn{6}{|l|}{ Served hot and fresh } \\
\hline \multicolumn{6}{|l|}{ Healthy } \\
\hline \multicolumn{6}{|c|}{ Very nutritious! } \\
\hline \multicolumn{6}{|c|}{ Proportion of vegetables and meat are balance. } \\
\hline \multicolumn{6}{|l|}{ Good variety of items } \\
\hline \multicolumn{6}{|l|}{ Food Preparation } \\
\hline \multicolumn{6}{|l|}{ Excellent } \\
\hline \multicolumn{6}{|l|}{ The menu board was easy to read } \\
\hline Employees are friendly and courteous & & & & & \\
\hline
\end{tabular}

